\title{
Animal Detection System in Farm Areas
}

\author{
Vikhram.B ${ }^{1}$, Revathi. ${ }^{2}$, Shanmugapriya. $R^{3}$, Sowmiya. $S^{4}$, Pragadeeswaran.G ${ }^{5}$ \\ UG Scholar, Electronics and Communication Engineering, Info institute of Engineering, Coimbatore, India ${ }^{1234}$ \\ Assistant Professor, Electronics and Communication Engineering, Info Institute of Engineering, Coimbatore, India ${ }^{5}$
}

\begin{abstract}
The main aim of our project is to protect the crops from damage caused by animal as well as divert the animal without any harm.Animal detection system is designed to detect the presence of animal and offer a warning. In this project we used PIR and ultrasonic sensors to detect the movement of the animal and send signal to the controller .It diverts the animal by producing sound and signal further, this signal is transmitted to GSM and which gives an alert to farmers and forest department immediately.
\end{abstract}

Keywords: PIC 16F877A, PIR sensor, ultrasonic sensor, APR board.

\section{INTRODUCTION}

Due to over population it occurs a deforestation this results in shortage of food, water and shelter in forest areas. So, Animals interference in residential areas is increasing day by day which affects human life and property causes human animal conflict but as per nature's rule every living creature on this earth has important role in eco-system.

Agriculture is the backbone of the economy but because of animal interference in agricultural lands, there will be huge loss of crops. Elephants and other animals coming in to contact with humans, impact negatively in various means such as by depredation of crops, damaging grain stores, water supplies, houses and other assets, injuring and death of humans.

Farmers in India face serious threats from pests, natural calamities \&damage by animals resulting in lower yields Traditional methods followed by farmers are not that effective and it is not feasible to hire guards to keep an eye on crops and prevent wild animals. Since safety of both human and animal is equally vital.

So, animal detection system is necessary in farm areas.

\section{RELATED WORK}

Traditional electric fence has been helpful as a guard of crops. However, that system has some problems such as it cannot notify the voltage which occasionally drops. Furthermore, the owners of the fence have to check the voltage but they cannot know it without going there .An electric fence management system we develop uses wireless communication, and it enables the owners to know the voltage and the state of the electric fence and monitor it from remote locations safely. It describes a demonstrative experiment in a mountainous region, and suggests an approach to resolve some problems. An electric fence system using wireless network technology has been developed. The system consists of several observers and a display, the farmers are able to measure voltage at the fence, and have an ability to show it. The observers transmit the voltage with the direction of the voltage leak to the display. The display shows the received data and the owners can know the state of the electric fence.

DISADVANTAGE:

Harmful to animals.

\section{SPECIFICATIONS}

PIC16F877A: The microcontroller that has been used for this project is pic series.PIC microcontroller is the first RISC based microcontroller fabricated in CMOS (complementary metal oxide semiconductor) that uses separate bus for instruction and data allowing simultaneous access of program and data memory.The main advantage of CMOS and RIC combination is low power consumption resulting in avery small chip size with a small pin count. The main advantage of CMOS is that it has immunity to noise than other fabrication techniques.Program flash:8k;Data memory: 368 bytes;Data EEPROM: 258 bytes

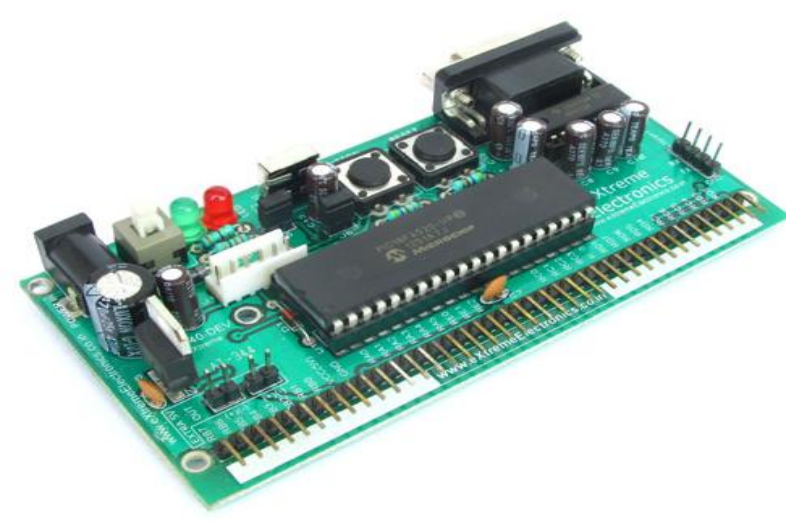

PIR SENSOR:A passive infrared sensor (PIR sensor) is an electronic device that measures infrared (IR) light radiating from objects in its field of view. Apparent motion is detected when an infrared source with one 
temperature, such as a human, passes in front of an infrared source with another temperature, such as a wall.PIR sensor detects a human being moving around within approximately $10 \mathrm{~m}$ from the sensor. This is an average value, as the actual detection range is between $5 \mathrm{~m}$ and $12 \mathrm{~m}$ Power is usually up to $5 \mathrm{~V}$.

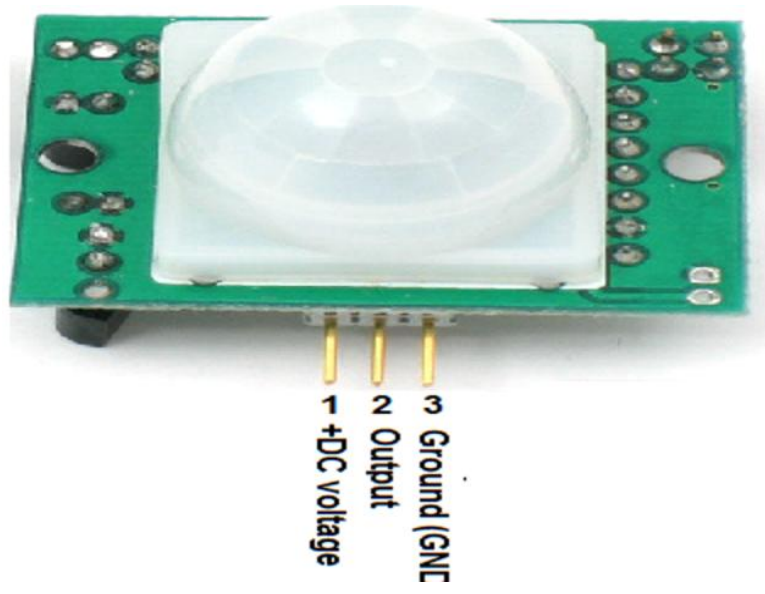

ULTRASONIC SENSOR: Ultrasonic ranging module $\mathrm{HC}$ - SR04 provides $2 \mathrm{~cm}-400 \mathrm{~cm}$ non-contact measurement function, the ranging accuracy can reach to $3 \mathrm{~mm}$. The modules includes ultrasonic transmitters, receiver and control circuit. When an electrical pulse of high voltage is applied to the ultrasonic transducer it vibrates across a specific spectrum of frequencies and generates a burst of sound waves. Whenever any obstacle comes ahead of the ultrasonic sensor the sound waves will reflect back in the form of echo and generates an electric pulse. It calculates the time taken between sending sound waves and receiving echo.working voltage of $5 \mathrm{~V}$.
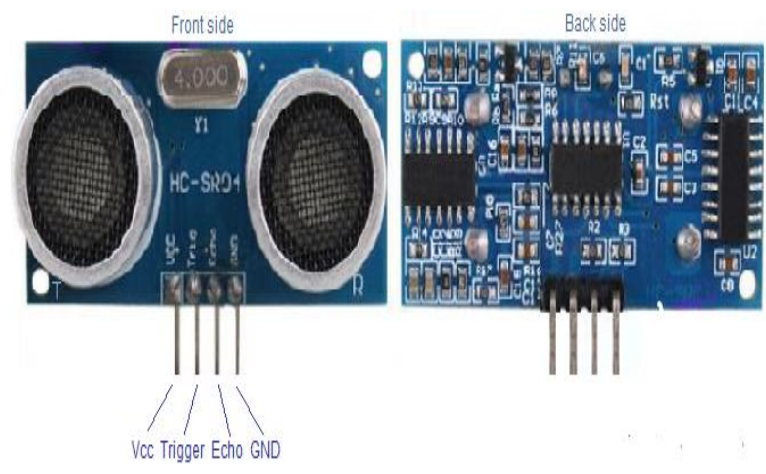

LCD DSPLAYS: There are many display devices used by the hobbyists. LCD displays are one of the most sophisticated display devices used by them. Once you learn how to interface it, it will be the easiest and very reliable output device used by you. More, for micro controller based project, not every time any debugger can be used. So LCD displays can be used to test the outputs. Obviously, for last possibility, you need to know how to use this stuff pretty well. Hitachi has set up a mile stone by its LCD controller IC. one of the IC $\mathrm{s}$ based upon the architecture introduced by Hitachi.

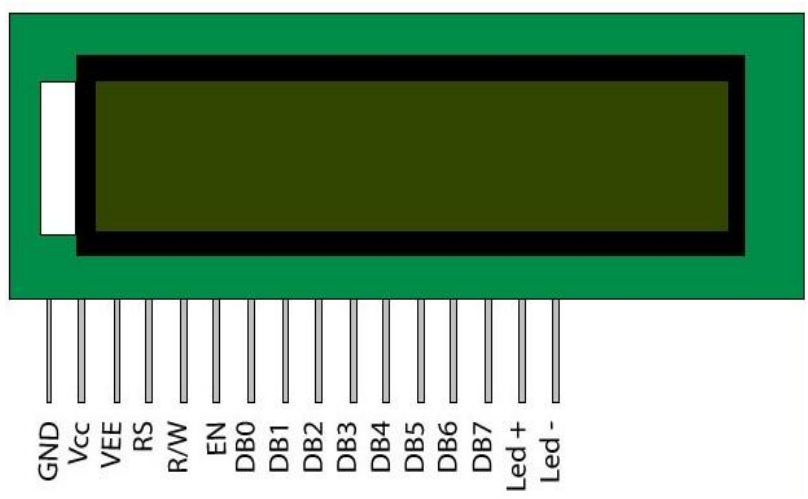

LIGHT DEPENDENT RESISTORS:An LDR or light dependent resistor is also known as photo resistor, photocell, photoconductor.It is a one type of resistor whose resistance varies depending on the amount of light falling on its surface. When the light falls on the resistor, then the resistance changes. These resistors are often used in many circuits where it is required to sense the presence of light. These resistors have a variety of functions and resistance. For instance, when the LDR is in darkness, then it can be used to turn ON a light or to turn OFF a light when it is in the light. A typical light dependent resistor has a resistance in the darkness of $1 \mathrm{MOhm}$, and in the brightness a resistance of a couple of KOhm. These devices depend on the light, when light falls on the LDR then the resistance decreases, and increases in the dark. When a LDR is kept in the dark place, its resistance is high and, when the LDR is kept in the light its resistance will decrease.
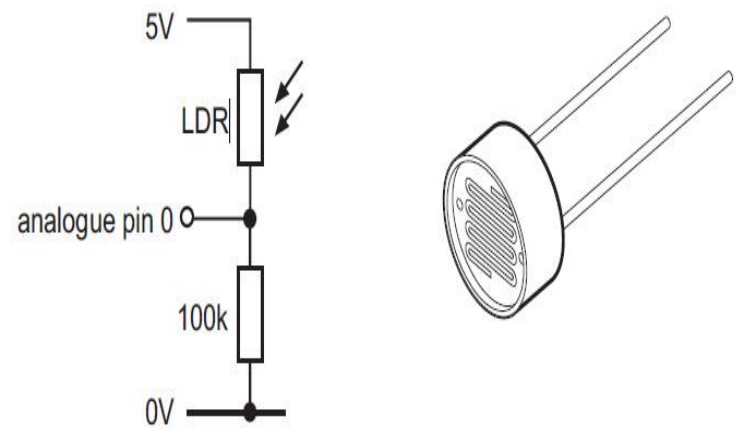

GSM SIM900A MODEM:GSM SIM900A ModemSIM900A, works on frequencies 900/ $1800 \mathrm{MHz}$. The Modem is coming with RS232 interface, which allows you connect PC as well as microcontroller with RS232 Chip(MAX232). The baud rate isconfigurable from 9600115200 through AT command.

The GSM/GPRS Modem is having internal TCP/IP stack to enable you to connect with internet via GPRS. It is suitable for SMS, Voice as well as DATA transfer application in M2M interface. The onboard Regulated Power supply allows you to connect wide range unregulated power supply. Using thismodem, you can make audio calls, SMS, Read SMS, attend the incoming calls and internet through simple AT commands. 


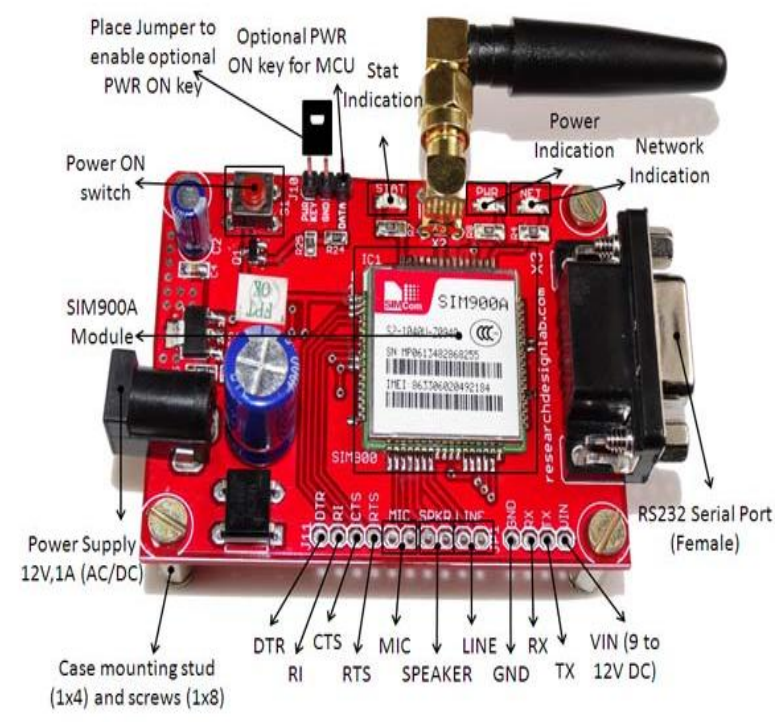

\section{APR (AUDIO VOICE RECORDER \&} PLAYBACK):The aPR33A3 are powerful audio processor along with high performance audio analog-todigital converters (ADCs) and digital-to-analog converters (DACs). The aPR33A3 incorporates all the functionality required to perform demanding audio/voice applications. High quality audio/voice.

Systems with lower bill-of-material costs can be implemented with the aPR33A3 because of its integrated analog data converters and full suite of quality enhancing features such as sample-rate convertor.

The aPR33A3 is specially designed for simple key trigger, user can record and playback the message averagely for 1 , 2,4 or 8 voice message(s) by switch, It is suitable in simple interface or need to limit the length of single message.

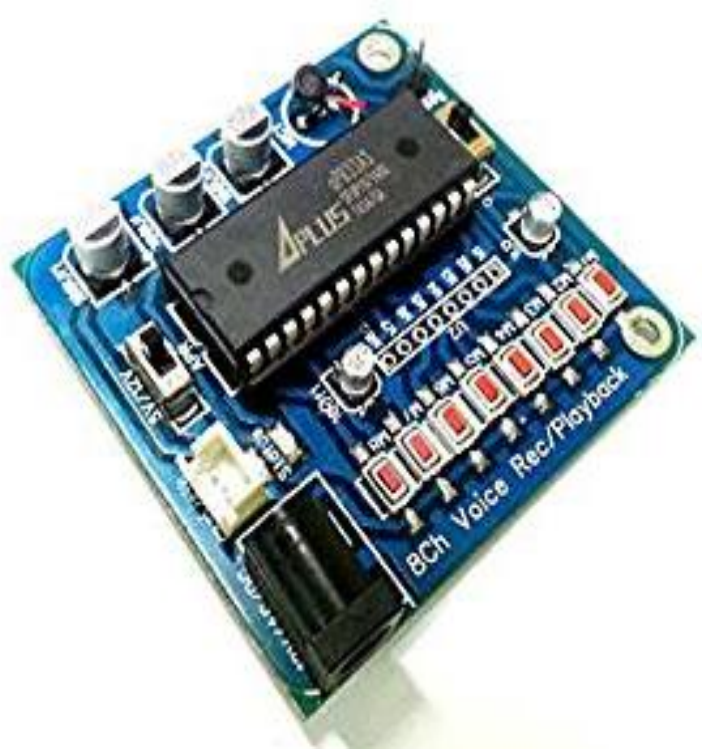

IV. BLOCK DIAGRAM

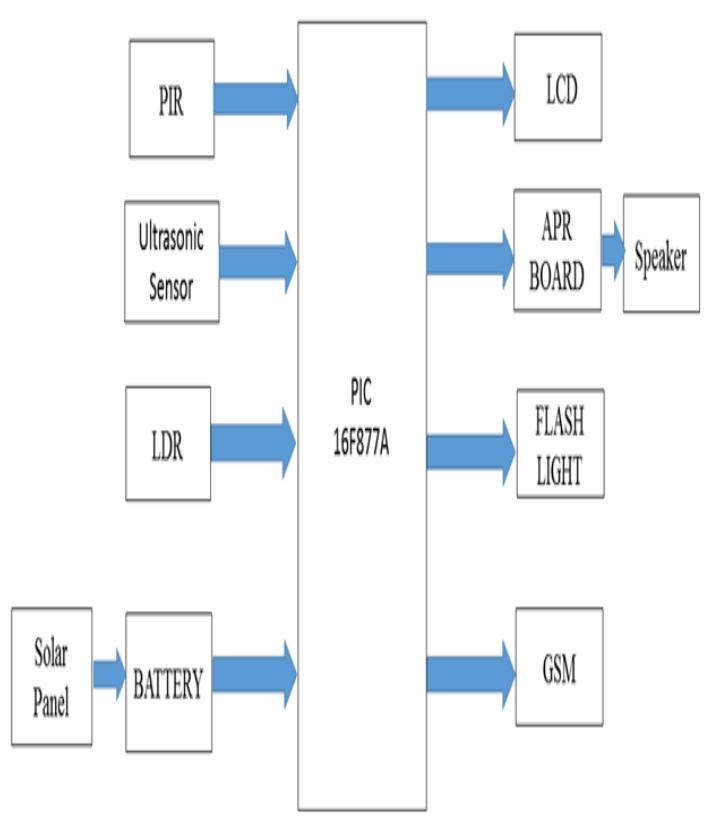

V. WORKING

In our proposed work, when the animal enter into the farm area. The PIR and ultrasonic sensor detect the presence of the animal and send an input signal to the controller. Immediately, the APR board will be on, and the sound is played to divert the animal. During night time the flash light will be on and the message will be send to the forest department and a call to the farmer.

Power supply will be given by the solar panel or from regulated power supply. The LCD display the presence of animal and LDR readings. The GSM module is used for sending SMS and make call.

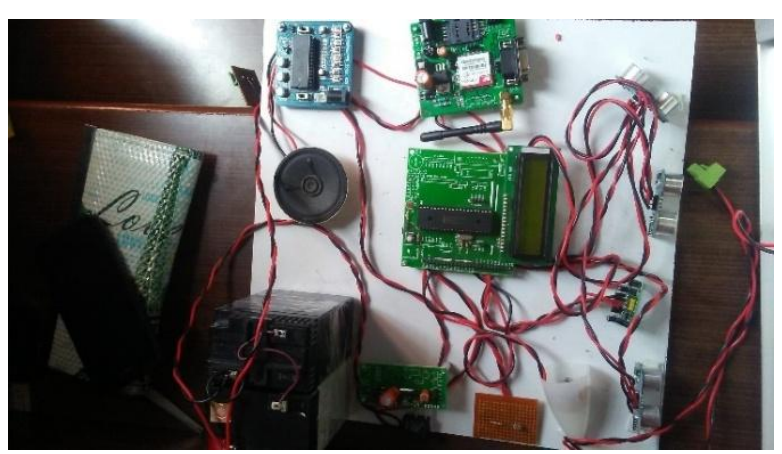

VI. SIMULATION

Tools used :proteus 8

Platform used : Windows XP 32bit

System configuration : core i3 (1.7GHZ)

Result : POSITIVE 

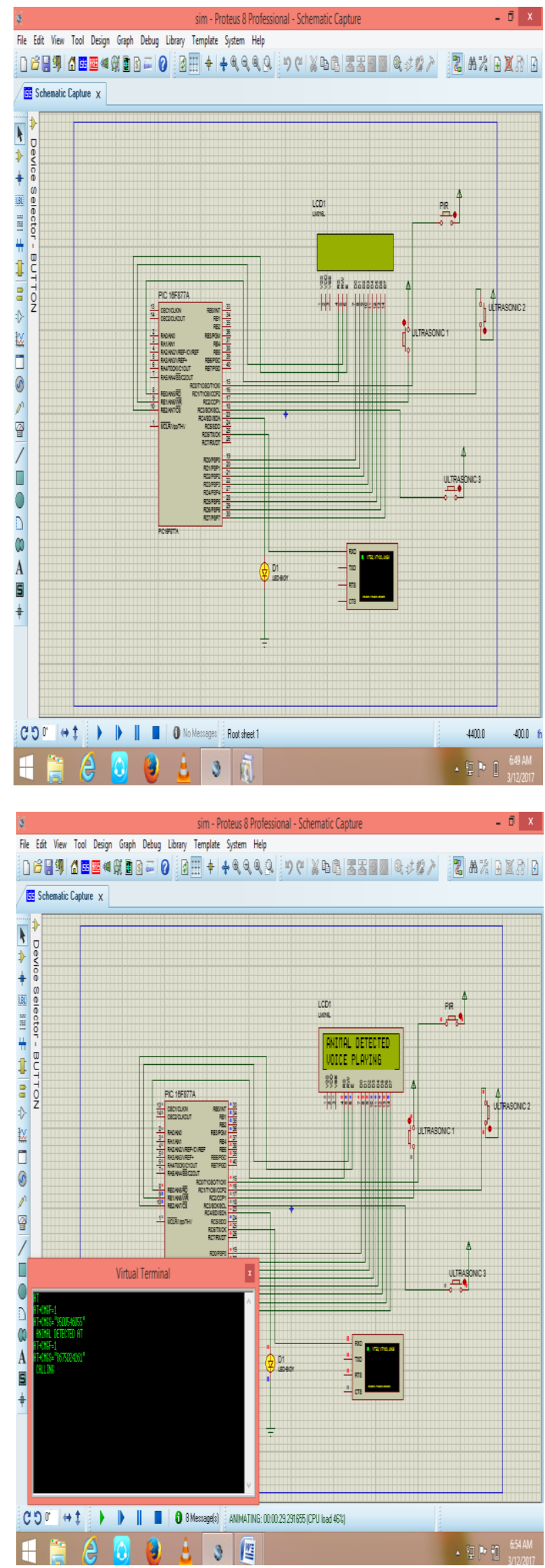

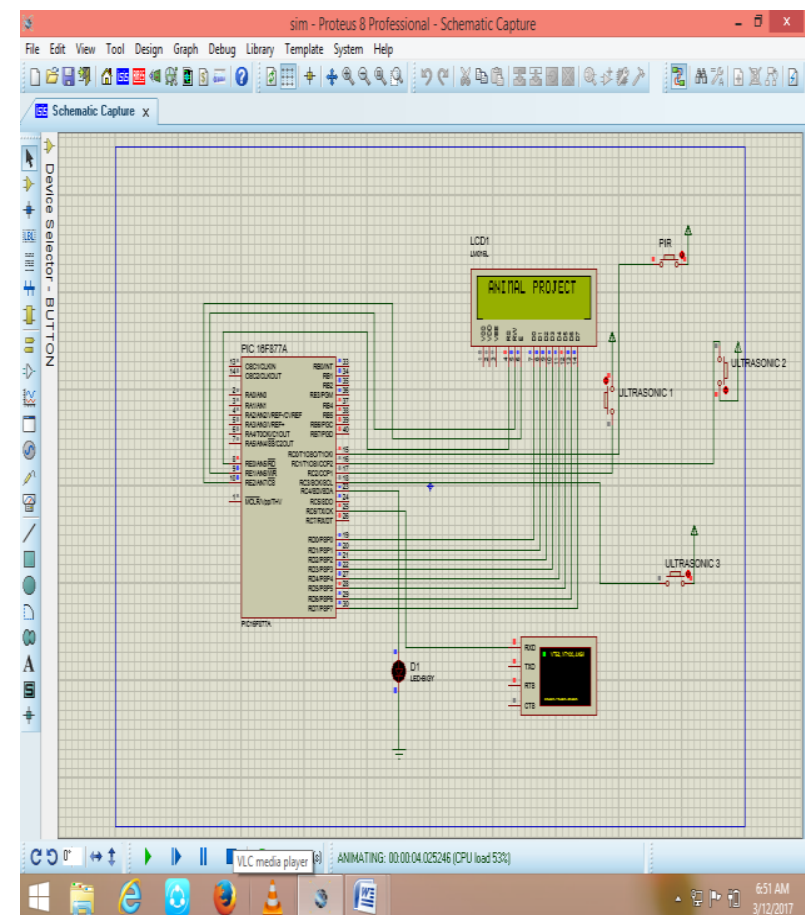

\section{LAND SURVEY}

We implemented \& tested the module in foot hills of Western Ghats in nilgiris biosphere Place surveyed :ANAKATTI ,TAMIL NADU
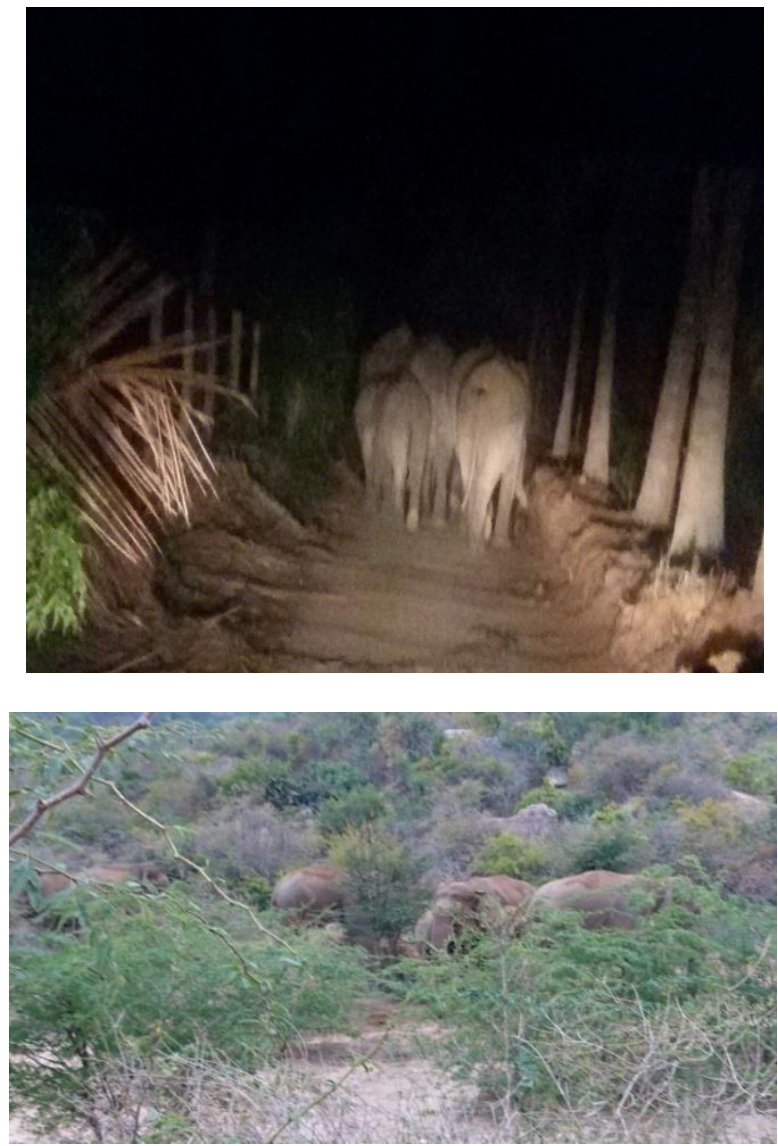

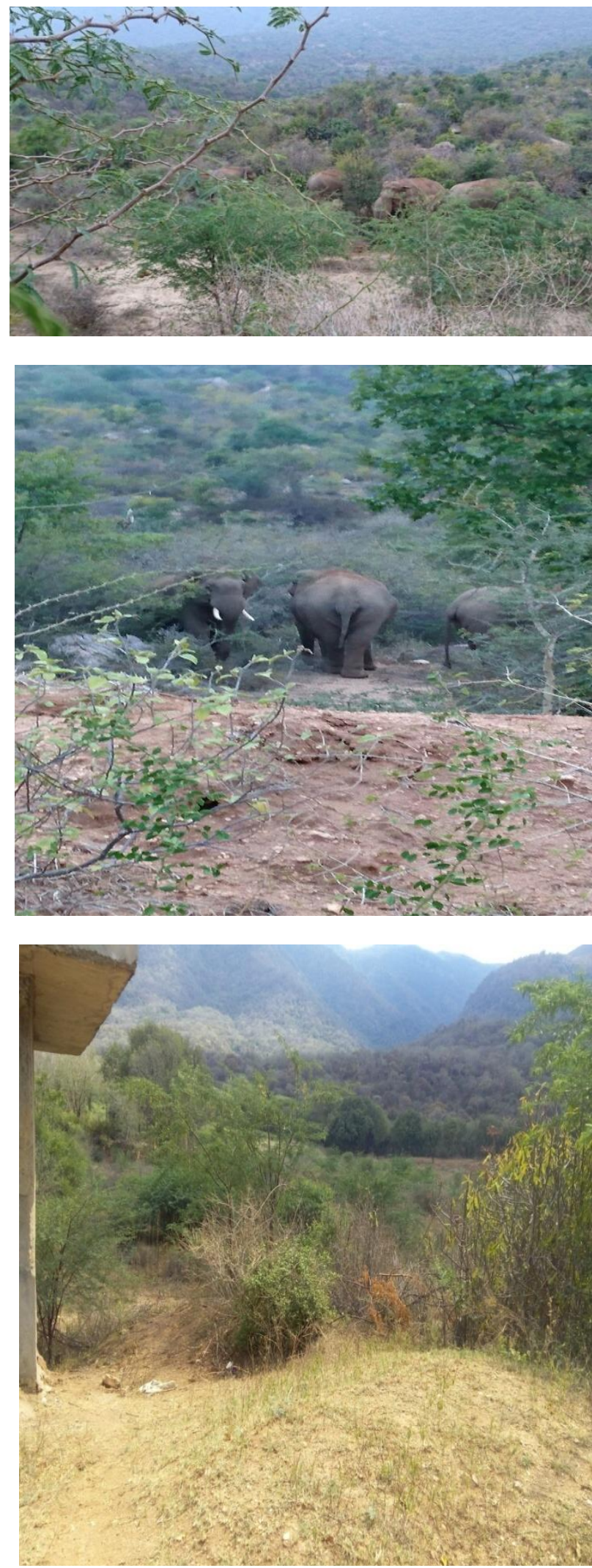

\section{CONCLUSION}

In rural parts of India, farmers encounter severe threats such as damage done by animals. Hence, to overcome this issue we have designed a system in which sound is played and by using LDR it detects light intensity, if it is less, it will focus the light. So that wild animals will not enter into the farm. It will run away. GSM module sends message to the farmer to alert him. From this it is concluded that the design system is very useful and affordable to the farmer. The design system will not be dangerous to animal and human being, and it protects farm.

\section{FUTURE ENHANCEMENT}

In the future, there will be very large scope, this project can be made based on wireless networks. Wireless sensor network and sensors of different types are used to collect the information of crop conditions and environmental changes and these information is transmitted through network to the farmer that initiates corrective actions. Farmers are connected and aware of the conditions of the agricultural field at anytime and anywhere in the world.

\section{REFERENCES}

[1] ArturFrankiewicz; RafałCupek."Smart Passive Infrared Sensor Hardware Platform" Year: 2013 IECON 2013 - 39th Annual Conference of the IEEE Industrial Electronics Society Pages: 7543 -7547,

[2] DOI: 10.1109/IECON.2013.6700389 CITED BY: PAPERS (1)

[3] Hanshi Wang; Jingli Lu; Lizhen Liu; Wei Song; Zhaoxia Wang; "Community Alarm System Design Based On MCU And GSM" Year: 2015

[4] Volume:01 Pages:859-862, DOI:10.1109/ICCSNT.2015.7490876, IEEE Conference Publications.

[5] Markus Borschbach; Navya Amin ,"Quality Of Obstacle Distance Measurement Using Ultrasonic Sensor And Precision Of Two Computer Vision-Based Obstacle Detection Approaches" Year: 2015, 2015 International Conference on Smart Sensors and Systems (IC-SSS)

[6] Pages: 1-6, DOI: 10.1109/SMARTSENS.2015.7873595IEEE Conference Publications

[7] Mustapha, Baharuddin, AladinZayegh, and Rezaul K. Begg. "Ultrasonic And Infrared Sensors Performance In A Wireless Obstacle Detection System" Artificial Intelligence, Modelling and Simulation (AIMS), 2013 1st International Conference on. IEEE, 2013.

[8] Dr. Wilson, "Electric Fence" Handbook of Texas, Project report published by the Texas State Historical Association. August 4, 2011

[9] T. Mohammad, "Using Ultrasonic And Infrared Sensors For Distance Measurement" World Academy of Science, Engineering and Technology, pp. 293-298, 2009.

[10] Discant, A. Rogozan, C. Rusu and A. Bensrhair, "Sensors For Obstacle Detection" 2007 30th International Spring Seminar on Electronics Technology (ISSE), Cluj-Napoca, 2007, pp. 100-105. doi: 10.1109/ISSE.2007.4432828 